\title{
GAMBARAN KERUSAKAN GIGI PASCA RESTORASI KOMPOSIT PADA SISWA SMA NEGERI 1 MANADO
}

\author{
${ }^{1}$ Angela Maggie Tambahani \\ ${ }^{2}$ Dinar Wicaksono \\ ${ }^{2}$ Ellen Tumewu
}

\author{
${ }^{1}$ Kandidat Skripsi Program Studi Kedokteran Gigi Fakultas Kedokteran \\ Universitas Sam Ratulangi Manado \\ ${ }^{2}$ Program Studi Kedokteran Gigi Fakultas Kedokteran Universitas Sam Ratulangi Manado \\ Email: sanchay_bwell@yahoo.com
}

\begin{abstract}
Composite resin in general refers to the addition of a polymer used to repair enamel and dentin. Composite resin are used to replace tooth structure and modify the shape and color of the teeth so that it can eventually restore function. The composite resin is formed by three main components namely the matrix resin, fillers, and particle coupling materials. On this research use descriptive research design. The purpose of this research is to know the tooth decay picture post composite restoration on a SMA Negeri 1 Manado student. Conclusion of the research is the number of female respondents who use the composite restoration more than male respondents. Most restoration gleaned from the result of this research are class I by G.V Black. Tooth decay after the composite restoration occurred most frequently is the black lines, then followed by secondary caries, tooth sensitivity and color change, while the least amount of tooth fracture or restoration.
\end{abstract}

Keywords : Composite restoration, respondents.

\begin{abstract}
Abstrak: Resin komposit secara umum mengacu pada penambahan polimer yang digunakan untuk memperbaiki enamel dan dentin. Resin komposit digunakan untuk mengganti struktur gigi dan memodifikasi bentuk dan warna gigi sehingga akhirnya dapat mengembalikan fungsinya. Resin komposit dibentuk oleh tiga komponen utama yaitu resin matriks, partikel bahan pengisi dan bahan coupling. Pada penelitian ini menggunankan rancangan penelitian deskriptif. Tujuan dari penelitian ini adalah untuk mengetahui gambaran tipe restorasi dan kerusakan gigi pasca restorasi komposit pada siswa di SMA Negeri 1 Manado. Kesimpulan pada penelitian ini adalah jumlah responden perempuan yang menggunakan restorasi komposit lebih banyak dibandingkan dengan responden laki-laki. Restorasi yang paling banyak diperoleh dari hasil penelitian ini adalah kelas I menurut G.V Black.Kerusakan gigi pasca restorasi komposit yang terjadi paling banyak adalah garis hitam, selanjutnya diikuti oleh karies sekunder, kemudian sensitivitas gigi dan perubahan warna sedangkan paling sedikit adalah fraktur gigi atau restorasi.
\end{abstract}

Kata kunci: Restorasi komposit dan responden.

Karies merupakan suatu penyakit jaringan keras gigi yaitu email, dentin, dan sementum yang disebabkan oleh aktivitas suatu jasad renik dalam suatu karbohidrat yang dapat diragikan. Beberapa jenis karbohidrat misalnya sukrosa dan glukosa membentuk asam sehingga $\mathrm{pH}$ plak menurun sampai di bawah 5. Penurunan $\mathrm{pH}$ dalam waktu tertentu akan mengakibatkan demineralisasi gigi yang rentan dan proses kariespun dimulai. Gigi yang telah terkena karies butuh perhatian khusus untuk dirawat agar gigi tetap bertahan di dalam rongga mulut. Bahan restorasi dapat mengembalikan estetik merupakan kebutuhan masyarakat saat ini. Bahan restotasi resin komposit saat ini sudah berkembang sangat pesat dan dapat memberikan hasil restorasi yang baik, 
yaitu memiliki kriteria estetis yang memadai dan kekuatan serta ketahanannya juga meningkat. Penggunaan bahan resin komposit saat ini sudah semakin meluas. Kerusakan jaringan keras gigi, baik pada gigi-gigi anterior maupun posterior, dapat restorasi menggunakan resin komposit. ${ }^{1}$

Saat ini, banyak pilihan bagi dokter gigi dan pasien dalam memilih material untuk merestorasi gigi yang karies, beberapa faktor yang mempengaruhi material yang digunakan diantaranya kekuatan, ketahanan dan stabilitas dimensi serta warna dari material tersebut. Hal-hal tersebut sangat mempengaruhi pasien untuk memilih material apa yang ingin mereka gunakan.

Pencapaian estetik merupakan kelebihan utama dari resin komposit. Resin komposit memiliki berbagai keuntungan seperti memiliki resistensi yang baik, mempunyai daya absorbsi air yang rendah, melekat dengan mudah pada permukaan gigi,warna yang mudah disesuaikan dan mudah dimanipulasi. Proses pengerasan resin komposit dapat dengan menggunakan alat Visible Light Cure (VLC). ${ }^{2}$

Walaupun banyak mempunyai kelebihan dalam hal estetik dan kekuatan, namun beberapa peneliti menyatakan bahwa bahan tersebut memiliki beberapa kelemahan, diantaranya berupa sifat iritasinya terhadap jaringan pulpa serta adaptasi yang kurang baik pada dinding kavitas. Kegagalan restorasi resin komposit dapat disebabkan oleh beberapa faktor diantaranya, lingkungan mulut bersifat asam, kelembaban, mikroflora dalam rongga mulut, email dan dentin. Akibat kegagalan ini dapat terjadi kebocoran tepi pada resin komposit. $^{3}$

Tidak semua kasus kerusakan jaringan keras gigi dapat diatasi dengan menggunakan bahan resin komposit, resin komposit dapat berikatan dengan email dan dentin secara mikromekanis. Email dan dentin yang telah dietsa memungkinkan resin komposit untuk berikatan melalui porositas yang terbentuk pada permukaan jaringan keras gigi tersebut. ${ }^{4}$

Secara klinis ditemukan kelemahan resin komposit yaitu, menurunnya kekerasan resin komposit, gigi sensitif setelah prosedur perawatan, munculnya garis hitam pada daerah batas antara restorasi dan gigi, terbentuknya karies sekunder,warna resin komposit dapat berubah seriring berjalannya waktu jika pasien merokok, mengkonsumsi kopi, teh, atau makanan yang mengandung zat pewarna. Kelemahan-kelemahan ini dapat mengganggu kenyamanan pasien sehingga hal ini perlu mendapat perhatian serius dari dokter gigi. ${ }^{5}$

SMA Negeri 1 Manado adalah Sekolah Menengah Atas Negeri yang pertama kali didirikan di kota Manado, yang beralamat di Jl.Pramuka No. 102 kelurahan Sario Kotabaru, kecamatan Sario, Manado, Sulawesi Utara. Tercatat siswa di SMA Negeri 1 Manado pada tahun 2011 mencapai 2101 siswa dan merupakan siswa terbanyak di seluruh Sekolah Menengah Atas yang ada di Sulawesi Utara. Berdasarkan latar belakang tersebut, maka penulis akan mengadakan penelitian tentang gambaran tipe restorasi dan kerusakan gigi pasca restorasi komposit pada siswa di SMA Negeri 1 Manado.

\section{METODE PENELITIAN}

Jenis penelitian yang digunakan yaitu penelitian deskriptif potong lintang. Penelitian dilakukan di SMA Negeri 1 Manado pada bulan Januari 2012 sesuai dengan kesepakatan antara pihak sekolah dengan penulis. Populasi target pada penelitian ini adalah siswa di SMA Negeri 1 Manado yang memiliki restorasi komposit dengan jumlah 225 siswa. Besar sampel yang diambil menggunakan metode purposif sampel dan dalam penelitian ini ditentukan dengan menggunakan rumus perhitungan besar sampel sebagai berikut:

$$
\begin{aligned}
& \mathrm{n}=\frac{N}{N(d)^{2}+1} \\
& =\frac{225}{225(0.05)^{2}+1} \quad \begin{array}{l}
\text { Dimana: } \\
\mathrm{n}=\text { Jumlah Sampel }
\end{array} \\
& =144 \mathrm{~d}=\text { Deviasi, Diambil } 5 \%
\end{aligned}
$$


Kriteria sampel dibagi menjadi 2 yaitu: Kriteria inklusi (Siswa di SMA Negeri 1 Manado, Memiliki restorasi komposit, Bersedia menjadi sampel penelitian) dan Kriteria eksklusi (Tidak bersedia menjadi sampel penelitian, Tidak hadir pada saat penelitian, Tidak diizinkan oleh orang tua). Pada penelitian ini, variabel yang diambil adalah jenis kelamin, tipe restorasi, jenis kerusakan. Definisi operasional variabel: Jenis kelamin dibagi menjadi 2 yaitu lakilaki dan perempuan. Tipe restorasi adalah klasifikasi restorasi menurut G.V. Black, kelas I, II, III, IV, V dan VI. ${ }^{2}$ Umumnya, komposit digunakan pada prosedur restorasi berikut, yaitu: Restorasi kelas I: restorasi pada permukaan oklusal gigi posterior, dua pertiga oklusal dari permukaan fasial dan lingual gigi molar, dan permukaan palatal gigi anterior rahang atas. Restorasi kelas II: restorasi pada satu atau kedua permukaan proksimal gigi posterior. Restorasi kelas III: restorasi pada permukaan mesial atau distal dari gigi insisivus atau kaninus. Restorasi kelas IV: restorasi pada permukaan proksimal gigi anterior yang telah meluas sampai ke sudut insisal. Restorasi kelas V: restorasi pada $1 / 3$ diatas servikal bagian bukal gigi posterior. Jenis kerusakan yang dimaksud adalah jenis kerusakan pasca restorasi komposit yaitu: Karies sekunder adalah karies yang menyebar dibawah atau di dalam tepi restorasi, disebabkan oleh akumulasi debris akibat tidak sempurnanya preparasi kavitas. ${ }^{6}$ Perubahan warna adalah berubahnya warna di sekitar gigi akibat adanya restorasi komposit. ${ }^{7}$ Fraktur gigi/ restorasi adalah patahnya gigi atau restorasi yang dapat menyebabkan terpisahnya restorasi dari kavitas. Sensitifitas gigi adalah rasa ngilu yang mucul akibat perubahan suhu (panas/dingin). Garis hitam adalah garis yang biasanya muncul pada daerah batas antara restorasi dan gigi. Pada penelitian ini digunakan instrumen diagnostik (kaca mulut, sonde, pinset dan ekskavator), sarung tangan, masker, cairan antiseptik, alkohol, air bersih, gelas kumur, alat tulis menulis dan formulir wawancara. Proses pengumpulan data dilakukan pada saat kegiatan belajar mengajar di sekolah dengan ijin pengambilan data dan penelitian yang diperoleh dari Kepala SMA N 1 Manado.

Data yang diperoleh dari penelitian ini, diolah dan dianalisis kemudian disajikan dalam bentuk tabel atau diagram.

\section{HASIL PENELITIAN}

\section{Jenis responden}

Responden dalam penelitian ini adalah siswa-siswi SMA Negeri 1 Manado yang memiliki restorasi komposit dan bersedia menjadi sampel dalam penelitian berjumlah 144 orang yang terdiri dari laki-laki 54 orang $(37,5 \%)$ dan perempuan 90 orang (62,5\%) (Gambar 1).

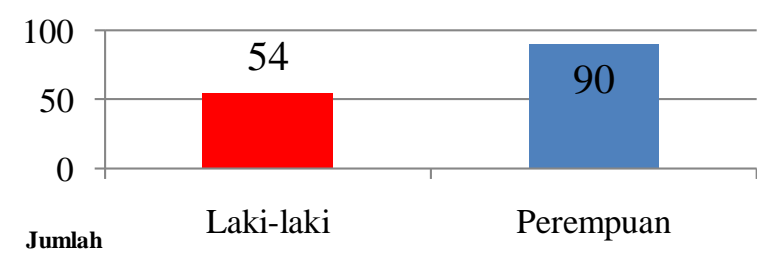

Gambar 1. Distribusi restorasi komposit berdasarkan jenis kelamin.

\section{Distribusi restorasi komposit berdasar- kan tipe restorasi}

Dari hasil penelitian didapatkan 155 restorasi dengan distribusi restorasi komposit (Gambar 2) berdasarkan tipe restorasi yaitu kelas I berjumlah 86 restorasi (55,5\%), kelas II berjumlah 14 restorasi (9.0\%), kelas III berjumlah 36 restorasi (23,2\%), kelas IV berjumlah 12 restorasi $(7,7 \%)$ dan kelas $\mathrm{V}$ berjumlah 7 restorasi $(4,5 \%)$.

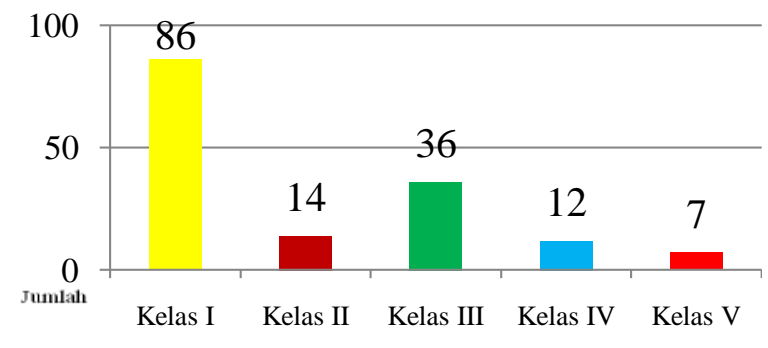

Gambar 2. Distribusi restorasi komposit berdasarkan jenis kelamin. 
124 Jurnal e-GiGi (eG), Volume 1, Nomor 2, September 2013, hlm. 121-128

\section{Distribusi tipe restorasi pada responden laki-laki}

Pada penelitian yang dilakukan di SMA Negeri 1 Manado didapatkan hasil distribusi tipe restorasi pada (Gambar 3) responden laki-laki sebanyak 58 restorasi dengan rincian kelas I berjumlah 49 restorasi $(84,5 \%)$, kelas II berjumlah 5 restorasi (8.6\%), kelas III berjumlah 1 restorasi (1,7\%), kelas IV berjumlah 1 restorasi $(1,7 \%)$ dan kelas $\mathrm{V}$ berjumlah 2 restorasi $(3,4 \%)$.

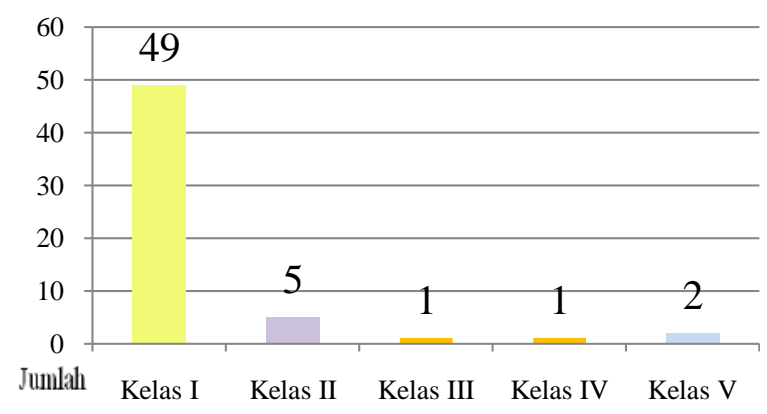

Gambar 3. Distribusi restorasi komposit pada responden laki-laki.

\section{Disrtibusi tipe restorasi pada responden perempuan}

Hasil penelitian menunjukan bahwa distribusi tipe restorasi pada responden perempuan (Gambar 4) adalah sebanyak 97 restorasi dengan rincihan kelas I berjumlah 37 restorasi (38,1\%), kelas II berjumlah 9 restorasi $(9,2 \%)$, kelas III berjumlah 35 restorasi (36,1\%), kelas IV berjumlah 11 restorasi $(11,3 \%)$ dan kelas $\mathrm{V}$ berjumlah 5 restorasi $(5,2 \%)$.

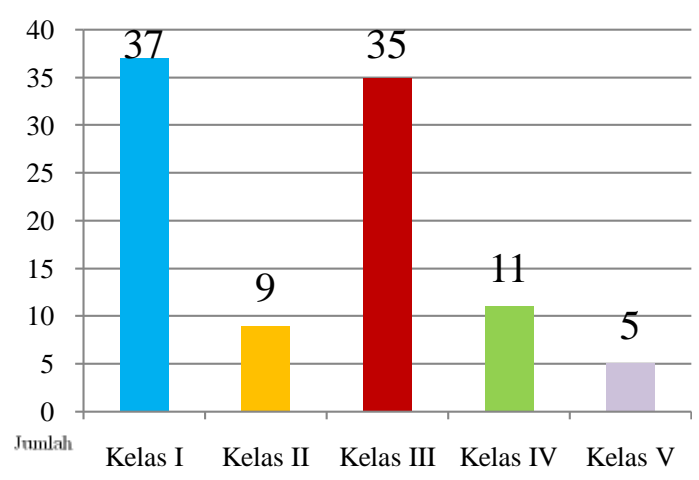

Gambar 4. Distribusi restorasi komposit pada responden perempuan.

\section{Distribusi kerusakan gigi pasca restorasi komposit berdasarkan jenis kerusakan}

Dari 155 restorasi (Gambar 5) hasil penelitian mendapatkan sebanyak 257 kerusakan yang terjadi dan dikelompokkan berdasarkan kerusakan yaitu karies sekunder 52 kerusakan $(20,2 \%)$, perubahan warna 18 kerusakan (7,0\%), fraktur gigi/restorasi 18 kerusakan (7,0\%), sensitifitas gigi $57(22,2 \%)$ dan garis hitam 112 kerusakan (43,6\%).

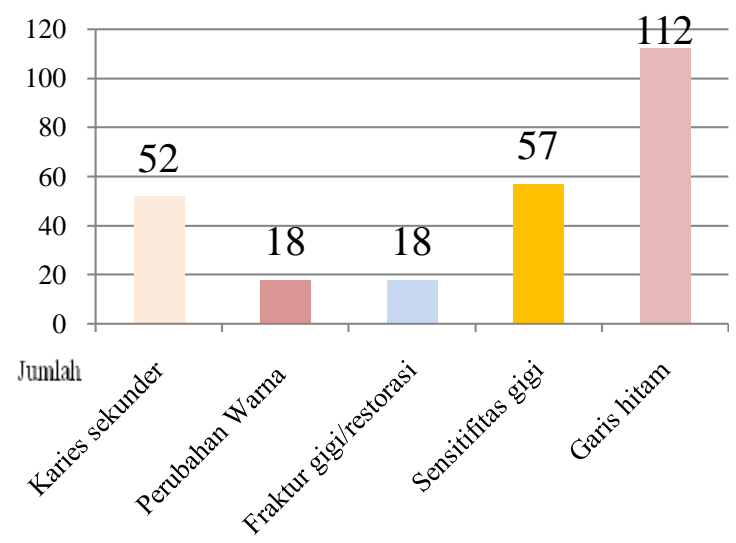

Gambar 5. Distribusi kerusakan restorasi komposit berdasarkan jenis kerusakan.

\section{Distribusi kerusakan gigi pasca restorasi komposit pada restorasi kelas I}

Pada restorasi kelas I (Gambar 6) didapatkan 160 kerusakan yang terjadi dengan perincihan yaitu karies sekunder 35 kerusakan (21,9\%), perubahan warna 10 kerusakan (6,3\%), fraktur gigi/restorasi 15 kerusakan (79,4\%), sensitifitas gigi 38 (23,8\%) dan garis hitam 62 kerusakan (38,8\%).

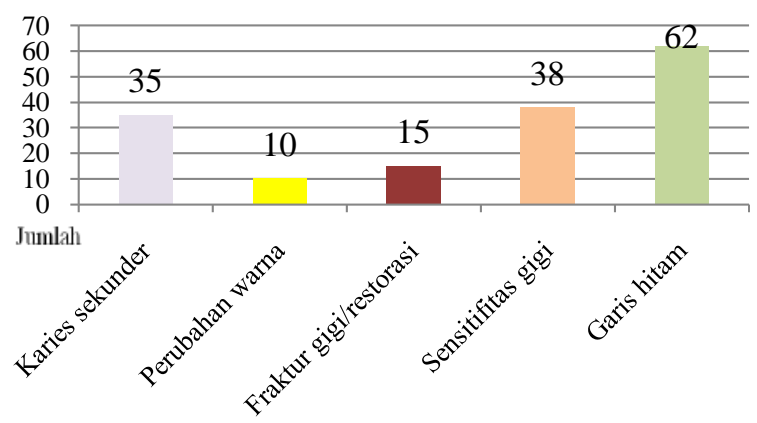

Gambar 6. Distribusi kerusakan gigi pasca restorasi komposit pada restorasi kelas I. 


\section{Distribusi kerusakan gigi pasca restorasi komposit pada restorasi kelas II}

Sebanyak 22 kerusakan yang terjadi pada restorasi kelas II (Gambar 7), masingmasing kerusakannya adalah karies sekunder 4 kerusakan (18,2\%), perubahan warna dan fraktur gigi/restorasi tidak ada, sensitifitas gigi $6(27,3 \%)$ dan garis hitam 12 kerusakan (54,5\%).

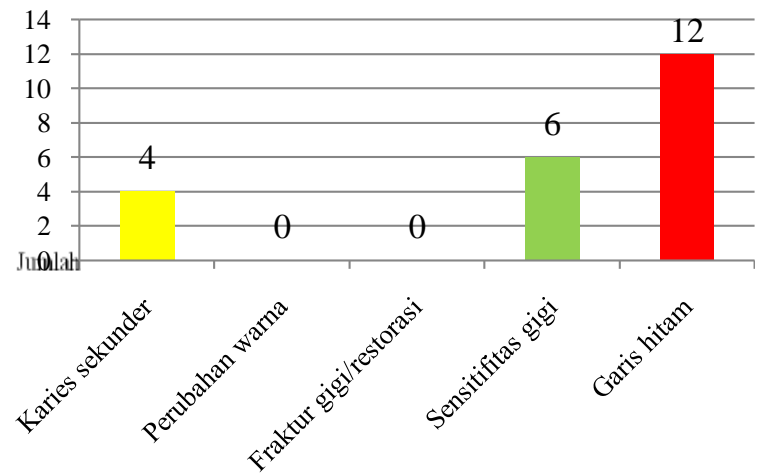

Gambar 7. Distribusi kerusakan gigi pasca restorasi komposit pada restorasi kelas II.

\section{Distribusi kerusakan gigi pasca restorasi komposit pada restorasi kelas III}

Hasil penelitian mendapatkan 54 kerusakan terjadi pada restorasi kelas III (Gambar 8) dengan rincihan karies sekunder 10 kerusakan (18,5\%), perubahan warna 7 kerusakan (12,9\%), fraktur gigi/restorasi 2 kerusakan (3,7\%), sensitifitas gigi $9(16,2 \%)$ dan garis hitam 26 kerusakan (48,1\%).

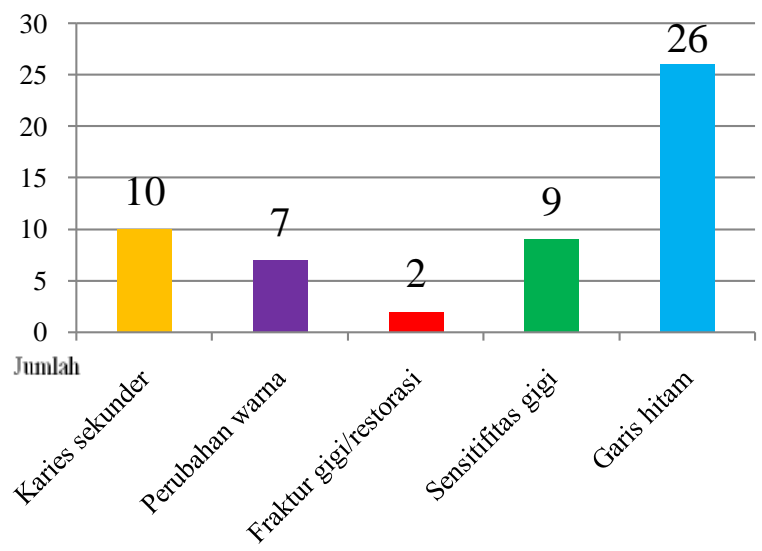

Gambar 8. Distribusi kerusakan gigi pasca restorasi komposit pada restorasi kelas III.
Distribusi kerusakan gigi pasca restorasi komposit pada restorasi kelas IV

Pada restorasi kelas IV (Gambar 9), didapatkan 12 kerusakan yaitu sensitifitas gigi 3 (25\%) dan garis hitam 9 kerusakan (75\%).

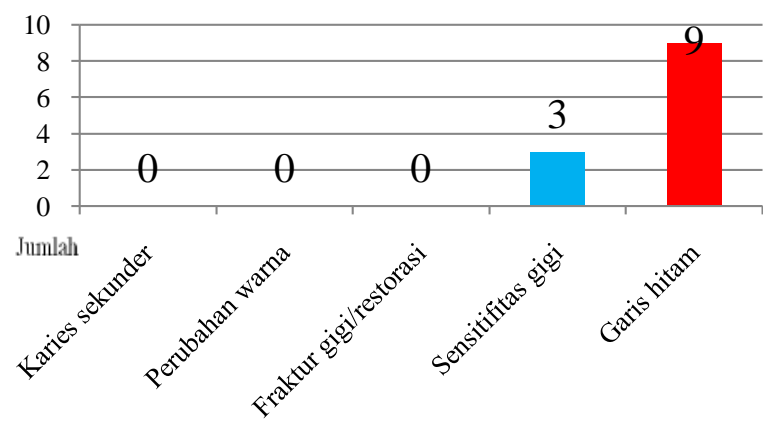

Gambar 9. Distribusi kerusakan gigi pasca restorasi komposit pada restorasi kelas IV.

\section{Distribusi kerusakan gigi pasca restorasi komposit pada restorasi kelas $\mathrm{V}$}

Sebanyak 10 kerusakan didapatkan pada restorasi kelas $\mathrm{V}$ yaitu karies sekunder 4 kerusakan (30\%), perubahan warna 1 kerusakan (10\%), fraktur gigi/restorasi tidak ada, sensitifitas gigi 2 (20\%) dan garis hitam 3 kerusakan (30\%) (Gambar 10).

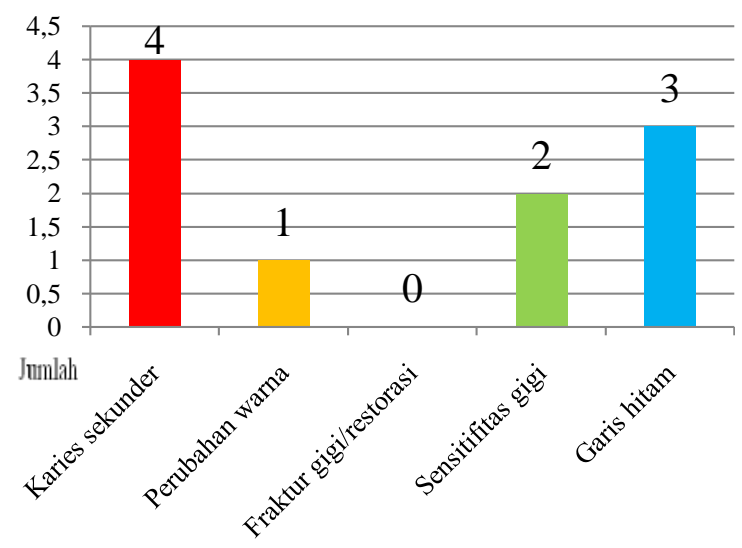

Gambar 10. Distribusi kerusakan gigi pasca restorasi komposit pada restorasi kelas V.

\section{BAHASAN}

Penelitian ini dilakukan pada siswasiswi SMA Negeri 1 Manado, jumlah sampel yang diteliti adalah sebanyak 144 
sampel dengan perolehan restorasi sebanyak 155 restorasi. Jumlah responden laki-laki 54 orang dan responden perempuan 90 orang.

Menurut G.V Black, karies kelas I dapat mengenai permukaan oklusal gigi posterior, dua pertiga oklusal dari permukaan fasial dan lingual gigi molar, dan permukaan palatal gigi anterior rahang atas. Jika tidak segera direstorasi maka akan menyebabkan penumpukan makanan yang dapat memicu terjadinya karies. ${ }^{2}$ Hermina dalam penelitiannya mengatakan bahwa meskipun terjadi kerusakan pada tambalan resin komposit klas I ternyata keuntungan yang nyata dari resin komposit klas I adalah daerah yang rusak dapat sering diperbaiki dengan cara meningkatkan perlekatan resin ke resin, seluruh permukaan restorasi yang tertinggal harus dibuat kasar dengan bur diamond dan permukaannya dibentuk kembali dengan resin baru, untuk menyempurnakan penempatan kembali restorasi dan juga mempertahankan struktur gigi, perawatan seperti ini biayanya menjadi murah.

Dari hasil penelitian, distribusi tipe restorasi pada responden laki-laki terdapat 58 restorasi dan yang paling banyak adalah restorasi kelas I yaitu 49 restorasi, restorasi kelas II berjumlah 5 restorasi sedangkan restorasi kelas III dan kelas IV hanya berjumlah 1 restorasi dan restorasi kelas $\mathrm{V}$ berjumlah 2 restorasi. Restorasi kelas I adalah restorasi pada permukaan oklusal gigi posterior, dua pertiga oklusal dari permukaan fasial dan lingual gigi molar, dan permukaan palatal gigi anterior rahang atas atau restorasi pada gigi molar, dan lebih banyak terjadi pada gigi molar 1 . Gigi molar 1 tumbuh lebih dahulu dibandikan gigi yang lain yaitu 90\% pada usia 6 tahun sehingga umur gigi molar lebih tua dari gigi lainnya, semakin tua umur gigi maka semakin lebih cepatlah kerusakannya. ${ }^{8}$

Hasil penelitian menunjukan bahwa distribusi kerusakan gigi pasca restorasi komposit pada perempuan adalah sebanyak 97 restorasi. Restorasi yang paling banyak digunakan adalah restorasi kelas I sebanyak 37 restorasikemudian secara berturut-turut diikuti oleh restorasi kelas III sebanyak 39 restorasi, restorasi kelas IV berjumlah 11 restorasi, restorasi kelas II sebanyak 9 restorasi dan terakhir restorasi kelas $\mathrm{V}$ berjumlah 5 restorasi. Umumnya perempuan sangat memperhatikan penampilan fisiknya sehingga ketika terjadi kerusakan pada daerah tubuh yang mempengaruhi penampilannya maka mereka akan segera mengatasi/memperbaiki masalah tersebut. Perempuan akan segera merestorasi giginya ketika terjadi kerusakan agar penampilannya tetap terlihan cantik dan menarik. ${ }^{9}$

Pada penelitian ini, dari 257 kerusakan yang terjadi, paling banyak adalah garis hitam sebanyak 112 kerusakan, kemudian diikuti oleh sensitifitas gigi 57 kerusakan, kemudian karies sekunder 52 kerusakan sedangkan perubahan warna dan fraktur gigi/restorasi berjumlah 18 kerusakan. Kebocoran tepi didefinisikan oleh Kidd sebagai celah mikroskopik antara dinding kavitas dan restorasi yang dapat dilalui mikro organisme, cairan, molekul dan ion. Kebocoran tersebut dapat mengakibatkan berbagai keadaan seperti karies sekunder, diskolorasi gigi, reaksi hipersensitif, bahkan dapat mempercepat, kerusakan restorasi itu sendiri. Terjadinya kebocoran tepi merupakan akibat kegagalan adaptasi restorasi terhadap dinding kavitas. Kobayashi (1973) menyatakan bahwa terdapat hubungan antara kebocoran tepi dan adaptasi restorasi. Kegagalan restorasi resin komposit dapat disebabkan oleh faktor berikut, perbedaan masing-masing koefisien thermal ekspansi diantara resin komposit, dentin dan enamel, penggunaan oklusi dan pengunyahan yang tidak normal, dan kesulitan karena adanya kelembaban, mikroflora yang ada, lingkungan mulut bersifat asam, maka akibat kegagalan ini dapat terjadi kebocoran tepi pada resin komposit. ${ }^{10}$

Pada restorasi kelas I didapatkan 160 kerusakan yang terjadi perincihan yaitu karies sekunder 35 kerusakan, perubahan warna 10 kerusakan, fraktur gigi/restorasi 15 kerusakan, sensitifitas gigi 38 kerusakan dan garis hitam 62 kerusakan. Data menunjukan bahwa garis hitam merupakan kerusakan yang paling banyak ditemui, garis hitam biasanya muncul pada batas antara restorasi dan gigi. 
Hasil penelitian menunjukan bahwa pada restorasi kelas II didapatkan 22 kerusakan yaitu 12 garis hitam, 6 sensitifitas gigi dan 4 karies sekunder, restorasi kelas II adalah pada satu atau kedua permukaan proksimal gigi posterior. Pradopo dalam penelitiannya mengatakan ketahanan restorasi bergantung pada beberapa faktor meliputi jenis gigi, lokasi, tipe restorasi, umur pasien, serta bahan yang digunakan. Karies sekunder merupakan penyebab tersering kegagalan atau kerusakan restorasi. ${ }^{11}$

Pada 144 responden yang diteliti, data menunjukan bahwa terjadi 54 kerusakan pada restorasi kelas III diantaranya garis hitam 26 kerusakan, karies sekunder 10 kerusakan, sensitifitas gigi 9 kerusakan, perubahan warna 7 kerusakan dan fraktur gigi/restorasi 2 kerusakan. Hal ini menunjukan bahwa garis hitam merupakan kerusakan yang paling banyak dijumpai pada responden penelitian, garis hitam muncul pada batas antara restorasi dan gigi lama kelamaan jika tidak diperbaiki akan menyebabkan gigi sensitive karena dentin yang terbuka dan memicu terjadinya karies sekunder yang bias berakibat pada fraktur gigi atau restorasi, sementara perubahan warna yang terjadi biasanya akibat dari konsumsi makanan atau minuman yang mengandung zat-zat kimia tertentu. ${ }^{12,13}$

Pada restorasi kelas IV didapatkan 12 kerusakan yaitu 3 sensitifitas gigi dan 9 garis hitam. Restorasi kelas IV adalah restorasi pada permukaan proksimal gigi anterior yang telah meluas sampai ke sudut insisal. Garis hitam merupakan kerusakan yang paling banyak ditemui pada restorasi kelas IV. Kesalahan dalam proses restorasi dapat menyebabkan kegagalan dalam restorasi. $^{2}$

Distribusi kerusakan gigi pada restorasi kelas $\mathrm{V}$ berjumlah 10 kerusakan dengan masing-masing 4 karies sekunder, 1 perubahan warna, 2 sensitifitas gigi dan 3 garis hitam, karies sekunder merupakan kerusakan yang paling banyak terjadi. Tidak semua tindakan yang dilakukan oleh dokter gigi atau perawat gigi berhasil dengan sempurna, kadang karena keterbatasan manusia sering terjadi kegagalan dalam merestorasi gigi untuk itu perlu ketelitian dan kehati-hatian dalam melaksanakan tindakan agar kerusakan yang terjadi dapat diminimalisir. ${ }^{7}$

\section{SIMPULAN}

1. Jumlah responden perempuan yang menggunakan restorasi komposit lebih banyak dibandingkan dengan responden laki-laki.

2. Restorasi yang paling banyak diperoleh dari hasil penelitian ini adalah kelas I menurut G.V Black.

3. Kerusakan gigi pasca restorasi komposit yang terjadi paling banyak adalah garis hitam, selanjutnya diikuti oleh karies sekunder, kemudian sensitivitas gigi dan perubahan warna sedangkan paling sedikit adalah fraktur gigi.

4. Menjaga kebersihan gigi dan mulut sangatlah penting agar tidak terjadi kerusakan gigi. Rajin menyikat gigi pada waktu yang tepat, meneriksaan keadaan gigi dan mulut setiap 6 bulan sekali.

5. Diperlukan sosialisasi tentang pentingnya menjaga kebersihan gigi dan mulut dikalangan sekolah dan di lingkungan masyarakat.

6. Diperlukan penelitian lanjutan mengenai faktor-faktor penyebab kerusakan gigi pasca restorasi komposit di daerah lain.

\section{DAFTAR PUSTAKA}

1. Anusavice KJ. Buku ajar ilmu bahan kedokteran gigi (Edisi Kesepuluh). Jakarta: EGC, 2004; p.301-43.

2. Lund. Buku Ajar Ilmu Konservasi Gigi (Edisi Ketiga). Alih bahasa: Rasinta Tarigan. Jakarta: EGC; 1997.

3. Wicaksono, D Mariati NW. Ilmu Konservasi Gigi I Materi Perkuliahan. Manado: PSKG-UNSRAT; 2009.

4. Dharsono. Restorasi Resin Komposit dengan Teknik Laminasi [homepage on the Internet]. 2008 [cited 2011 Sep 28]. Available from: URL: http://resources. unpad.ac.id/unpadcontent/uploads/publikasi dosen/ESTORASI\%20RESIN\%20KOMPO SIT\%20DENGAN\%20TEKNIK\%20LAMI NASI.PDF.

5. Pengaruh ketebalan bahan dan lamanya 
128 Jurnal e-GiGi (eG), Volume 1, Nomor 2, September 2013, hlm. 121-128

waktu penyinaran terhadap kekerasan permukaan resin komposit sinar [serial online]. 2008 [cited 2011 Sep 28]. Available from: URL: http://journal.unair.ac.id/ filerPDF/DENTJ-38-1-09.pdf.

6. Kidd, Edwina AM, Joyston BS. Dasardasar Karies Penyakit dan Penanggulangannya. Alih bahasa: Sumawinata N, Faruk S. Jakarta: EGC, 1991; p.168-201.

7. Kegagalan restorasi resin komposit dan solusinya [homepage on the Internet]. 2008 [cited 2011 Sep 28]. Available from: URL: $\quad$ http://doktergigibaik.wordpress. com/2011/03/29/kegagalan-restorasi-resinkomposit-dan-solusinya/.

8. Zahtur. Mengapa gigi geraham mudah rusak [homepage on the Internet]. Nodate [cited 2012 Mar 22]. Available from URL: http://id.answers.yahoo.com/question/index? qid=20100328112511AA5acm.

9. Heniputra. Wanita lebih peduli masalah kesehatan [homepage on the Internet].
Nodate [cited 2012 Apr 27]. Available from URL: http://heniputra.com/wanita-lebihpeduli-masalah-kesehatan.html

10. Hermina T. Perbaikan Restorasi Resin Komposit Klas I. [homepage on the Internet]. 2008 [cited 2011 Sep 28]. Available from: URL: http://repository.usu.ac.id/bitstream/123456 789/1180/1/fkghermina4. pdf.

11. Pradopo S, Saskianti T. Mengatasi kegagalan restorasi klas II pada gigi sulung. Dentika Dental Journal. 2007;12(1):75-80.

12. Mulyawati Y. Pengaruh rokok terhadap kesehatan gigi [homepage on the Internet]. 2008 [cited 2011 Sep 28]. Available from: URL: http://kesehatangigi.blogspot.com/ 2008/01/pengaruh-rokok-terhadapkesehatan-gigi.html

13. Wibowo A. Minuman beralkohol dan kesehatan mulut [homepage on the Internet]. 2011 [cited 2011 Sep 28]. Diunduh dari URL: http://www.medicalera.com/info_ answer.php?thread=11911 